\title{
Psychogenic Grunting: A Case Report
}

\author{
Shorouq Motwani ${ }^{1}$, Krishnapriya Murlimanohar $^{2}$, Sagar Karia ${ }^{3}$, Nilesh Shah ${ }^{4}$, Avinash Desousa $^{5}$
}

\begin{abstract}
Grunting may be a symptom that may be seen as a part of somatoform, conversion, and tic disorders. The symptom is distressing to both the patient and relatives around the patient. We present herewith the case of a 14-year-old adolescent girl who was referred to our outpatient department with psychogenic grunting and responded well to medications.

Keywords: Conversion disorder, Grunting, Psychogenic grunting, Somatoform disorder.

Indian Journal of Private Psychiatry (2020): 10.5005/jp-journals-10067-0047
\end{abstract}

\section{INTRODUCTION}

Persistent grunting, if psychological in nature, is a distressing problem that affects the patients and their relatives alike. The condition may be seen independently or as a part of psychogenic cough and tic-like disorders. ${ }^{1}$ These disorders usually begin in late to middle childhood, and coughing, sneezing, and grunting may be part of the spectrum seen. ${ }^{2}$ It is important that differential diagnoses like somatoform disorders, conversion disorders, and neurological disorders be ruled out before labeling the condition as psychogenic. ${ }^{3}$ It is also vital that using various methods a definite stressor be elicited before labeling the condition as psychogenic. ${ }^{4}$ A consultation-liaison approach where various subspecialties are consulted before a psychogenic conclusion is reached, is prudent in such cases. ${ }^{5}$

We present herewith the case of a 14-year-old adolescent that presented with persistent psychogenic grunting and responded to medication with a complete resolution of her symptoms.

\section{Case Report}

A 14-year-old adolescent girl was referred to the outpatient psychiatry department from the ENT (ear, nose, and throat) department with chief complaints of persistent grunting sounds for the past 2 to 3 months and academic deterioration over the same period. The patient had developed cough 3 months ago and was taken to the ENT outpatient department, and none of the usual medications provided relief from the cough. She was then referred for a psychiatric evaluation. She used to make these grunting and croaking sounds throughout the day except when she was talking, singing songs, eating food, or sleeping. The patient reported that the intensity of her sounds increased more so in the evening and her sleep and appetite had also decreased for the past 1 week. The girl's academic performance started deteriorating after the death of her maternal great-uncle 3 months back to whom she was very attached. She also started showing withdrawn behavior and easy irritability for a few days. The patient had no family history suggestive of psychiatric illness and her birth history was normal while she had delayed milestones by a few months in most of the milestones during the first 2 to 3 years of life. The patient was the child of a single parent and stayed with her mother as her parents had separated when she was 2 years old.

During the interview, she would talk but would grunt most of the time during the conversation. No abnormality on ${ }_{1-5}$ Department of Psychiatry, Lokmanya Tilak Municipal Medical
College, Mumbai, Maharashtra, India

Corresponding Author: Avinash Desousa, Department of Psychiatry, Lokmanya Tilak Municipal Medical College, Mumbai, Maharashtra, India, e-mail: avinashdes888@gmail.com

How to cite this article: Motwani S, Murlimanohar K, Karia S, et al. Psychogenic Grunting: A Case Report. Ind J Priv Psychiatry 2020;14(1):41-42.

Source of support: Nil

Conflict of interest: None

physical examination was noted, and the central nervous system examination was normal. Her mental status examination revealed no abnormality except for the grunting sounds. The patient was given a differential diagnosis of conversion disorder, psychogenic grunting, and tic disorder.

She was started on haloperidol at a dosage of $1.5 \mathrm{mg}$ twice a day, chlorpromazine at $25 \mathrm{mg}$ twice a day, baclofen at $10 \mathrm{mg}$ thrice a day, and clonazepam at $0.5 \mathrm{mg}$ twice a day in view of tics and probable anxiety. All routine blood investigations along with serum C-reactive protein (CRP) levels, serum ceruloplasmin, and erythrocyte sedimentation rate (ESR) were normal. She showed a complete resolution of symptoms in 3 days and was discharged. The symptoms relapsed in 15 days when she was slapped by her uncle for failure in a school test. She was then admitted, and all her medication was withdrawn. She complained of feeling depressed after her uncle hit her and was then started on escitalopram $10 \mathrm{mg}$ at night and clonazepam $0.25 \mathrm{mg}$ thrice a day. She showed complete improvement in her symptoms in 5 days and was discharged. Her uncle and she were called in for counseling sessions focusing on the interpersonal domain. The patient has been fine for a month on those medications and has been following up with us. The patient was also subjected to two interviews using sodium pentothal, but no stressor could be elicited.

\section{Discussion}

In the present case, there was no elicitable stressor, yet most specialists that saw the patient mentioned that there was no physical abnormality and the grunting was psychogenic in nature. The patient showed a complete response to psychotropic drugs and antidepressants, which indicated a psychological nature of 
the problem. Her laboratory investigations were also within normal limits. Psychogenic cough and grunting as well as belching have been reported in anecdotal case reports in the literature. ${ }^{6,7}$ There is a need for psychiatrists to be aware of these conditions as they may often be misdiagnosed as vocal or phonic tics or Tourette's syndrome and treated with the wrong medications. ${ }^{8}$ A judicious consultation-liaison approach and treatment with medications often make the condition very amenable to treatment.

\section{Acknowledgment}

Nil

\section{References}

1. Leary PM. Conversion disorder in childhood-diagnosed too late, investigated too much? J R Soc Med 2003;96(9):436-438. DOI: 10.1258/jrsm.96.9.436.

2. Kozlowska K, Palmer DM, Brown KJ, et al. Reduction of autonomic regulation in children and adolescents with conversion disorders. Psychosom Med 2015;77(4):356-370. DOI: 10.1097/ PSY.0000000000000184.

3. Bhatia MS, Chandra R, Vaid L. Psychogenic cough: a profile of 32 cases. Int J Psychiatr Med 2002;32(4):353-360. DOI: 10.2190/9CTG8FR7-FBQJ-181V.

4. Vertigan AE, Murad MH, Pringsheim T, et al. Somatic cough syndrome (previously referred to as psychogenic cough) and tic cough (previously referred to as habit cough) in adults and children. Chest 2015;148(1):24-31. DOI: 10.1378/chest.15-0423.

5. Dooley JM. Tic disorders in childhood. Semin Pediatr Neurol 2006;13(4):231-242. DOI: 10.1016/j.spen.2006.09.004.

6. Sharma P, Sharma PP, Chaudhary DP, et al. A case of psychogenic belching. J Psychiatr Assoc Nepal 2014;3(2):48-49. DOI: https://doi. org/10.3126/jpan.v3i2.12395.

7. Irwin RS, Glomb WB, Chang AB. Habit cough, tic cough, and psychogenic cough in adult and pediatric populations: ACCP evidence-based clinical practice guidelines. Chest 2006;129(1):174S179S. DOI: 10.1378/chest.129.1_suppl.174S.

8. Shaw RJ, Wamboldt M, Bursch B, et al. Practice patterns in pediatric consultation-liaison psychiatry: a national survey. Psychosomatics 2006;47(1):43-49. DOI: 10.1176/appi.psy.47.1.43 